OPEN ACCESS

Edited by:

Robert James Nicholls, University of East Anglia,

United Kingdom

Reviewed by:

Goneri Le Cozannet,

Bureau de Recherches Géologiques

et Minières, France

Dimitris Stagonas,

University of Cyprus, Cyprus

${ }^{*}$ Correspondence: Jonathan Simm

j.simm@hrwallingford.com

Specialty section:

This article was submitted to Coastal Ocean Processes, a section of the journal

Frontiers in Marine Science

Received: 06 May 2021

Accepted: 26 July 2021

Published: 25 August 2021

Citation:

Simm J, Gouldby B, Lumbroso D and Matthewson T (2021) Effective

Coastal Climate Services - An End-User Perspective for Resilient

Infrastructure.

Front. Mar. Sci. 8:706048. doi: 10.3389/fmars.2021.706048

\section{Effective Coastal Climate Services-An End-User Perspective for Resilient Infrastructure}

\author{
Jonathan Simm*, Ben Gouldby, Darren Lumbroso and Tom Matthewson \\ HR Wallingford, Wallingford, United Kingdom
}

This paper focusses on identifying the responses to coastal climate change that are of interest for decision-making by end users and the delivery and the necessary communication process for this information. The focus is on representation of climate (response) information in a form that provides sufficient clarity in the midst of uncertainty for end-users who are seeking to develop or maintain resilient infrastructure. The paper recommends that the use of the term climate services in situations unrelated to supporting adaptation to and mitigation of climate change should be avoided. Better investment decisions could be made if Bayesian frameworks were used to assign probabilities to RCP scenarios. Associated predictions need to cover all types of climate change influences not just sea level rise and ideally provide concurrent time series to allow evaluation of dependencies. Guidance on climate information published by official bodies needs to adopt a consistent approach, with a clear narrative that describes the transition from science to guidance. The form in which climate services information is needed for the required end user decisions needs careful thought, including appropriate communication of the associated uncertainties using good practices and experiences from related sectors.

Keywords: climate services, infrastructure, resilient, uncertainty, communication

\section{INTRODUCTION-THE SITUATION OF END-USERS SEEKING RESILIENT INFRASTRUCTURE}

This paper uses the definition of coastal climate services by Le Cozannet et al. (2017) as "any type of service using (coastal area) climate information and supporting adaptation to and mitigation of climate change." Most of the discussion in the literature of climate services has been on their development, implementation in policy and expected benefits (see e.g., Hewitt et al., 2012; Brasseur and Gallardo, 2016). This paper focusses instead more on their operationality. Furthermore whilst climate services information is essential for infrastructure creators and managers, climate change is only one of a number of considerations that practitioners need to address in developing and investing in sustainable and resilient infrastructure From the literature and interaction with end users, we infer that the creation and management of such infrastructure has a spectrum of requirements including: 
- "Everydayness." Coastal infrastructure assets need to function to deliver their everyday requirements, such as access, transportation, power supply, recreation, agriculture, environmental and ecological improvement (see e.g., CIRIA, 2013, p. 60-70), irrespective of socioeconomic and climate changes (including sea level rise). Investment decisions will inevitably reflect this need, recognizing that some public assets will have importance for the wider community surrounding the asset and should work for them as well. Ideally green solutions should be considered whenever possible as part of the investment mix which enable natural processes to continue as far as possible, including sustaining the coastal sediment balance and encouraging habitats.

- Survivability. Infrastructure assets need to survive extreme events, with risk of failure and/or downtime appropriately managed, taking into account the non-stationarity (in many cases increases in severity) of severe events. Deterministic approaches that focus on single design events have well-known limitations in the coastal context. Annual exceedance probability cannot be unambiguously defined when there are multiple variables that require consideration (Serinaldi, 2015; Gouldby et al., 2017) and hence probabilistic methods that require analysis of large numbers of different events are increasingly being applied to assess failure in terms of the structural response (e.g., Gouldby et al., 2017). Given the uncertainty of future events, the idea of "designing for exceedance," first articulated for urban drainage (see e.g., Digman et al., 2006), becomes important. In particular, understanding the performance of the structure in more extreme scenarios (than used within the design basis) and gaining insights into "cliff-edge effects becomes essential. This is identified as a specific requirement in some sectors, nuclear for example (Office for Nuclear Regulation [ONR], 2018). Such a resilience based approach requires a clear understanding of how the structural, hydraulic and geotechnical performance of infrastructure assets will be affected and an approach to manage any performance reductions (see e.g., Chester et al., 2021). For example, it is likely that any green solutions will need to be backed up by substantial conventional engineering measures.

- Recoverability. If damage or disruption does occur as a result of extreme events, then minimizing downtime and ensuring rapid recovery becomes essential. However, damaged infrastructure should be replaced with solutions that anticipate long-term changes in climate (as well as business and socio economic drivers), avoiding the presumption of replacing like for like and embracing opportunities for transformation in approach (see e.g., Royal Society, 2014).

In assessing the nature and form of climate services required to deliver such requirements, two main areas will be discussed: the required basic climate information likely to be relevant and the nature and format of processed information required about responses in order to support decision making. Two "use cases" of coastal nuclear power plants and coastal ports are used to illustrate some of the points made.

\section{END-USER ISSUES WITH BASIC COASTAL CLIMATE INFORMATION}

The three requirements for managing infrastructure in the face of climate change suggests that climate services need reliable probabilistic information across the range of parameters affected by climate change and across the spectrum of climate manifestations (from everyday to extreme), provided in a form where uncertainties are quantified. It also suggests that official guidance for assessing such matters should be unambiguous and without contradiction. This section addresses some issues related to these needs.

\section{Probabilities for Climate Change Scenarios}

Current guidance and data relating to coastal flooding and climate change, quantifies uncertainty in some aspects but not in others. For example, the UKCP18 information relating to sea level rise provides probabilistic estimates of sea level rise for given R. The general UK government guidance for flood risk assessments is based on the use of the RCP8.5 scenario and specifies the consideration of the upper 70th percentile for design and risk assessment with a suggestions to use the 95th percentile for sensitivity analysis. The guidance, in line with the approach described by Nicholls et al. (2014), also advises consideration of the $\mathrm{H}++$ scenario. These probabilistic estimates are conditional on the specific RCPs being realized. There is, however, no likelihood associated with the RCPs themselves. Risk-based decision making requires the quantification of uncertainty and therefore requires a likelihood to be associated with the RCPs. Whilst to many climate scientists this may seem an elusive goal, and beyond their remit, the lack of this information significantly hampers risk-based decision making for infrastructure investments of typical design life 100 years.

Quantifying the likelihood of a future RCPs (and the related Shared Socio-economic Pathways that are emerging (Riahi et al., 2017). Occurring would not be viable under a traditional frequentist framework; however, the well-known Bayesian Framework can be used for this purpose. The Bayesian framework supports quantification of uncertainty through the use of expert judgment (see e.g., Morriss, 1977), and also permits the reconciliation of conflicting multi-model forecasts through Bayesian consolidation of parameters. Further evidence to support likelihood assessment of RCPs is continuously emerging (see Hausfather and Peters, 2020, for example). This framework also provides a natural updating process that evolves when new evidence emerges.

Whilst there is extensive literature relating to climate change in this regard (Allen et al., 2001; Tebaldi et al., 2005; Smith et al., 2009; Qian et al., 2016, Oppenheimer et al., 2016), the approach has not yet filtered through to mainstream data sets and guidance that are applied in practice. It should, however, only be a matter of time for these approaches to be adopted within 
mainstream guidance, in which hopefully quantified estimates of the uncertainty of different scenarios will be provided.

\section{Understanding All Climate Change Influences-Not Just Sea Level Rise Other Key Influences}

Recognition that sea level rise is only one of many change drivers which need to be considered. Other changes affecting coasts may include average and extreme winds and waves, tide range and tidal streams, pressure on water supplies and risks to health from hotter summers (see for example, Wong et al., 2014; Vousdoukas et al., 2020).

\section{Scenarios of Concurrent Time Series for Coastal Forcings}

The need for concurrent time series data across a range of different forcings. This concurrent date is needed to facilitate analysis of dependencies and permit understanding of multiple source or compound flooding. Note that whilst concurrent forcing data series are available for typical marine parameters (e.g., water levels and waves), time series data to allow evaluation of dependencies between coastal forcing and other forcings such as rainfall and river flows is limited.

\section{Inconsistent Climate Information Guidance Published by Official Bodies}

Guidance on climate change allowances to apply in practice is underpinned by climate science. There is, however, often a need to distill complex processes with the many uncertainties discussed in the scientific literature into simplified allowances that are applied in practice. To date, in the UK at least, two problems appear to arise in this process: (1) thinking becomes disjointed and hence inconsistent data sets or scenarios are referenced in official guidance; (2) the narrative that describes the transition from the science to the guidance is not routinely published and this lack of transparency can potentially undermine the authority of the guidance and cause confusion for practitioners.

Examples of this in UK guidance include:

- $\mathbf{H}++$ scenario. The very high scenario used for sea level change $(\mathrm{H}++)$ is rarely updated at the same time as general climate projections.

- Storm surge: Both UKCP09 and UKCP18 (Palmer et al., 2018) could find no significant evidence for increase in storm surge. Pre UKCP18, the government guidance for allowance for storm surge under the $\mathrm{H}++$ scenario was 0.7 $\mathrm{m}$ to 2080 . The latest guidance for the $\mathrm{H}++$ scenario, post UKCP18, is $2 \mathrm{~mm}$ per year, equating to $0.13 \mathrm{~m}$ to 2080. This is a decrease in allowance of around $80 \%$. There is no accompanying discussion relating to this significant reduction.

- Storminess (storm surge sensitivity): Changes in storminess can potentially influence wind speeds, wave conditions and storm surges. All are directly related to mid-latitude storms. Neither UKCP09 or UKCP18 found significant evidence relating to changes in storminess.
Pre-UKCP18, there was a recommendation for sensitivity testing of increase to winds and waves of $10 \%$ for epochs of 2055 and onward, but no requirement for storm surge sensitivity (other than the allowance under the $\mathrm{H}++$ scenario). No explanation was given for why it was not necessary to test the sensitivity relating to increases in storm surge.

- Storminess (sensitivity to allowance): Even though no evidence was found of increases in storminess with either UKCP09 or UKCP18, the sensitivity tests advised pre UKCP18 were changed to required allowances in the latest guidance.

There is no doubt that climate science evolved and attitudes to risk change. Nevertheless, the updates to the published guidance can give the impression that these are somewhat arbitrary, and hence portray a lack of credibility. Publication of the narrative that justifies updates, or changes, to the guidance would alleviate the situation and provide more transparency.

\section{SUPPORTING END-USER DECISION MAKING BY CLIMATE SERVICES}

\section{Meaning of "Climate Services"}

Careful use of language when describing climate services. This includes the need to be clear where the service being offered is full coastal engineering/management and not just climate services, involving (full) evaluation of present day conditions/requirements and then variation/sensitivity analysis to understand the implications, e.g., of sea level rise. This lack of focus prevents users from perceiving easily the real added value of climate services for adaptation to sea-level rise. This challenge would be addressed by a more consistent restriction of the use of "climate services" as being related to mitigation of or adaptation to the effects of climate change, as in the definition of Le Cozannet et al. (2017) cited in section "'Introduction-The Situation of End-Users Seeking Resilient Infrastructure” above.

\section{Clear and Appropriate Communication}

Clear and appropriate communication leading to appropriate services delivery. Climate services is as much about process as product, engaging end-users and scientists in a two-way conversation which understands the outputs/outcomes in which the end-user is interested. For example, does the end user want the "answers" about responses to climate drivers (e.g., increased wave overtopping rates at sea walls) or would they prefer to be provided with a tool that they can use to explore alternative scenarios involving multiple hazards and impacts and from this to identify and prioritize adaptation strategies. The case of climate services for ports will be discussed below, where end users will want to take account of the likely life of the port infrastructure being evaluated, the operability of the port, resilience under extreme conditions, and the need to build future adaptability into present day port investments.

If end-users are using climate services information for public communication, the existing challenges of communicating 
natural hazard risks (see e.g., Arvai and Rivers, 2013) is compounded when the issue of climate change is added. It is therefore recommended that communication about climate services builds upon knowledge and lessons learned in communication practices (e.g., define clear role of each actor for communicating, etc.) in relevant related areas, e.g., risk management.

\section{Clarity About Acceptable Uncertainties for Both Basic and "Processed" Information}

Clarity about the limits/uncertainties on available information about climate change drivers and recognition of the fact that better quantified drivers may not resolve uncertainty in response predictions, if the physical process understanding of responses (e.g., wave overtopping) has greater uncertainties. As part of this, it is necessary to identify (if they are known) any "cliff edge" effects which may cause dramatic changes in responses. Communicating these uncertainties is a significant challenge and good communication needs to recognize (a) a realistic assessment of the available accuracy of the data (avoiding unwarranted implications of regional/local accuracy) and (b) the purpose for which the information will be used which may vary between different decisions.

For example, effective decisions of different types related to sea level rise could be made with input information ranging from (a) simple Red Amber Green classifications (based on ranges of expected sea level rise) through to (b) multiple possible future sea level rise growth curves, each with their uncertainty ranges.

\section{USE CASE 1-NUCLEAR POWER PLANTS ON THE COAST}

Decisions relating to climate change, and sea level rise scenarios, are particularly important in the design of new nuclear facilities, given the potential hazard, the long operational lifespan and decommissioning period (typically of the order of 100200 years). Within the UK, the Office for Nuclear Regulation (ONR) and the Environment Agency (EA) published a joint position following the UKCP18 update (Office for Nuclear Regulation and Environment Agency [ONR and EA], 2017, 2020). (Note that the operator (rather than ONR or EA) is responsible for the safety of nuclear plants.) The paper (Office for Nuclear Regulation and Environment Agency [ONR and EA], 2020) sets out the position each organization adopts with regard to climate change allowances and flooding:

- ONR indicate a starting point for climate change allowances could be based on a Medium High emission; this equates to RCP 4.5 from a UKCP18 Marine perspective and the percentile could be interpreted as the 84 th percentile (see Figure 1), as this is what is suggested is used as a starting point for uncertainties relating to other external hazards.

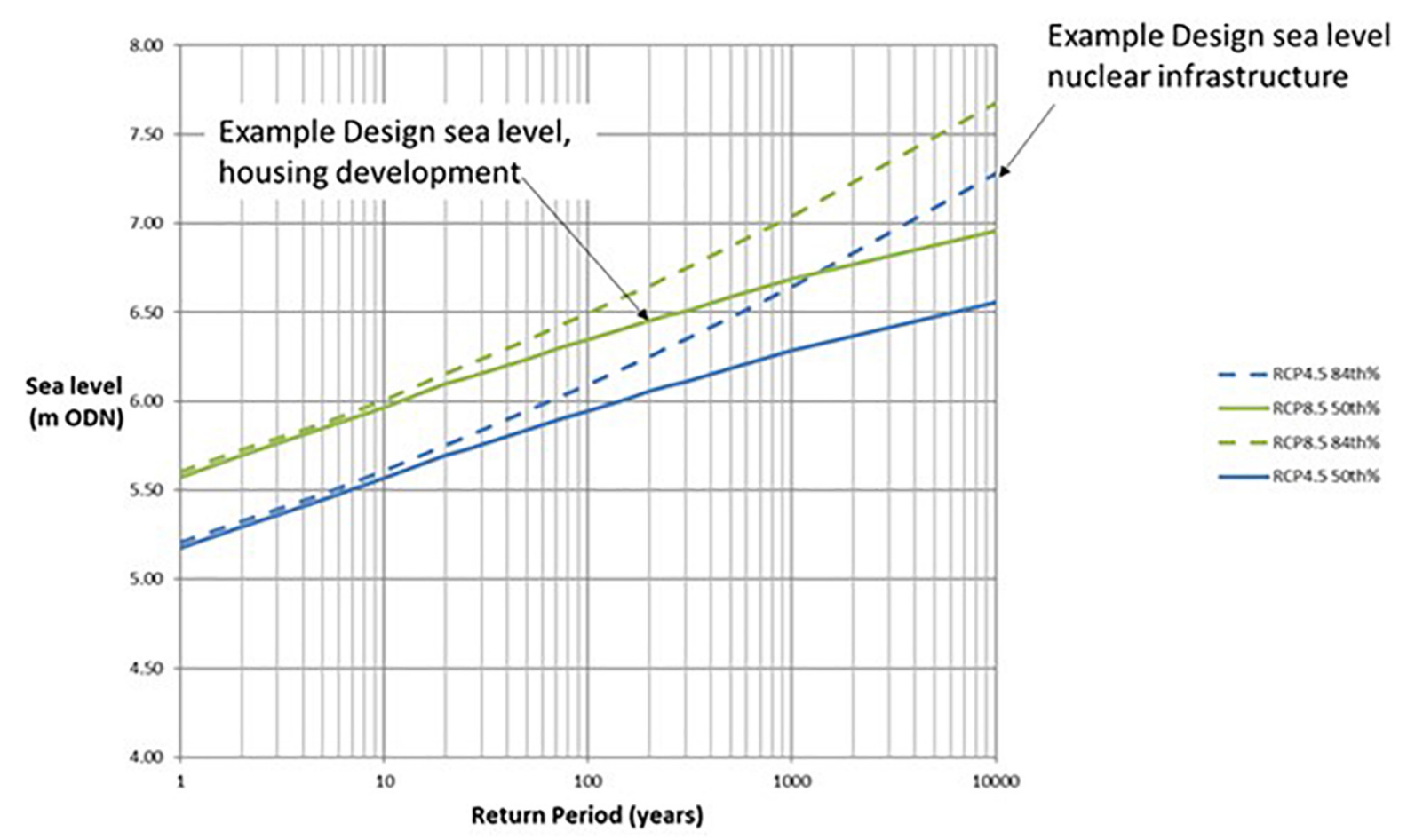

FIGURE 1 | Illustrative exemplar estimates of extreme sea levels for the year 2100 for different end applications for a hypothetical site. The figure utilizes the 9th percentile SLR estimate of the RCP8.5 and 4.5 scenarios, respectively. The percentile annotated in the legend relates to the uncertainty associated with the extrapolation of historical data to extreme values. 
They also recommend further sensitivity testing related to the $\mathrm{H}++$ scenario.

- EA guidance (Environment Agency [EA], 2020) prescribes RCP 8.5 and a 95th percentile for the sea level rise scenario (this was subsequently updated to the 70th percentile (for design) and 95th percentile (sensitivity), but implies use of the a 50th percentile when estimating the design return period events (see Figure 1). The EA guidance also requires consideration of the $\mathrm{H}++$ scenario.

It may appear to members of the public that the Environment Agency's design requirements are more stringent (conservative) than ONR's. In practice, however, higher return periods (i.e., nominal 10,000 years return period v 200 years return period) and related safety factors to account for uncertainty (84th percentile vs. 50th percentile) are used for nuclear facilities (see Figure 1). As would be expected, these return periods and safety factors provide more conservative design criteria, but there is a curious difference relating to the climate change scenarios discussed within the position statement.

The consideration of an ostensibly less stringent climate change scenario within the nuclear sector can cause challenges when communicating with a wider audience. The complexities around communicating uncertainties are further exacerbated by the two sets of percentiles being considered (for extrapolation and for sea level rise uncertainty). Furthermore, the motivation for different organizations adopting different climate change scenarios is not currently provided within the position statement. In the future, statements that provided some background relating to the statement could aid communication.

With regard to the development of new infrastructure, and also protecting existing infrastructure, there is significant current emphasis on a managed adaptive approach and incorporating flexibility (Office for Nuclear Regulation and Environment Agency [ONR and EA], 2017) into designs. This offers an attractive strategy for handling the uncertainty associated with climate change. The approach guards against the unnecessary initial over-design of infrastructure. An initial over-design can impose prohibitive upfront costs and unnecessary environmental implications in terms of the construction footprint and longerterm visual impairment.

Nevertheless, particularly in the case of construction of new infrastructure, there can be an unavoidable requirement to make non-reversible decisions. These could relate to the specification of the level of the footings (platform level) of a nuclear power station development, for example. In these situations, the emphasis can then shift to trading off climate change risks between the platform level for the construction of the new development and a flexible ability introduced within the flood defense component to manage the residual risk associated with climate change uncertainty. Significant research has been conducted into the benefits of adaptive flood defenses and how the economics of these can be used to manage climate change uncertainties (e.g., Woodward et al., 2012; Woodward et al., 2014; Guthrie, 2021).

\section{USE CASE 2-COASTAL PORTS}

Ports are not just subject to sea level rise. A number of other climate drivers (National Committee on Coastal and Ocean Engineering [NCCOE], 2004; Stenek et al., 2011; Lumbroso and Woodhouse, 2014) are important including changes to:

- Extreme waves/storm surge, which may damage breakwaters, berthing infrastructure and floating assets and create delays and disruption to port operations.

- Long term wave and current climates, which may increase sedimentation and scour.

- Extremes of rainfall resulting in both river floods and low flows, which may increase sediment loads and damage assets or limit navigation.

- Extreme rainfall resulting in surface water flooding and disruption to port landside operations.

- High winds, damaging vessels and tall assets such as cranes and creating operational delays.

As indicated in Table 1, climate services are required for ports both for decision making for routine operations in the short to medium term, but also in the long term for decision making for port planning and infrastructure investment.

When considering infrastructure investment, the anticipated life of the various types of port assets has a big impact on the extent to which climate change needs to be considered. Port investments often fall into two broad categories: those such as crane systems which will probably only have a life of the order of a generation (i.e., around 30 years or less) and those such as breakwaters and quay structures which are anticipated to last (in some form) for a number of generations (at least 100 years).

For investment in single generation assets, it is likely that investment decisions will primarily be influenced by factors other than climate change, such as ship capacity/dwt, required speed of turnaround, storage and transshipment.

TABLE 1 | Types of climate services and decision-making processes potentially supported (after Lumbroso and Woodhouse, 2014).

\begin{tabular}{|c|c|c|c|}
\hline & $\begin{array}{l}\text { Short term ( }<10 \text { days) weather } \\
\text { forecasting }\end{array}$ & $\begin{array}{l}\text { Medium term ( } 10 \text { days to } 1 \text { year) } \\
\text { seasonal weather forecasting }\end{array}$ & $\begin{array}{l}\text { Long term ( }>10 \text { years) climate change } \\
\text { projections, and baseline climate }\end{array}$ \\
\hline Climate services & $\begin{array}{l}\text { Short term forecasts of key variables such } \\
\text { as wave agitation (heights, periods, } \\
\text { directions) wind speed, storm surge }\end{array}$ & $\begin{array}{l}\text { Medium term forecasts of storminess, } \\
\text { extreme tide levels }\end{array}$ & $\begin{array}{l}\text { Historical climate data Assessments of the } \\
\text { impacts of observed hazards Projections of } \\
\text { change in key variables such as sea level, } \\
\text { wave heights, wind speed, storm surge }\end{array}$ \\
\hline Decision making processes & $\begin{array}{l}\text { Managing risks to operational activities } \\
\text { such as berthing and cargo handling }\end{array}$ & $\begin{array}{l}\text { Planning and scheduling operational } \\
\text { activities, e.g., maintenance }\end{array}$ & $\begin{array}{l}\text { Strategic port planning Feasibility and } \\
\text { design of infrastructure }\end{array}$ \\
\hline
\end{tabular}


For investment in multi-generational assets, their capacity to be adapted for climate change should become a much bigger consideration, as this affects the delivery of 24/7 operations, survival of extreme events and post extreme event adaptation.

Future adaptation options for the above may include:

- Ensuring appropriate levels of robustness for a range of future conditions, including building in allowances for increases at the time of construction/installation.

- Investments in tangible assets such as provisions to facilitate future raising of the crest of breakwaters, the operating level of quay walls and berthing/mooring facilities at quay walls.

- Advance planning for replacement structures in the event of damage/failure. The philosophy of the Sendai Build Back Better disaster recovery framework (United Nations Office for Disaster Risk Reduction [UNISDR], 2015) applies here and requires advance planning to avoid a knee-jerk reaction to replace structures on a like-for-like basis.

A mix of measures is therefore needed to adapt to climate change in ports, according to the nature of port operations, assets and their risk exposure. PIANC provides international guidance (PIANC - World Association for Waterborne Transport Infrastructure., 2020) on such a portfolio of measures, which lists a wide range of options (structural, operational and institutional) for adapting or strengthening the resilience of navigation infrastructure assets, operations and systems. Methodologies are also described in PIANC - World Association for Waterborne Transport Infrastructure. (2020) for conducting climate change risk assessment in existing ports. These use quantitative evaluation of multiple hazards and impacts to provide port managers with essential information to identify and prioritize adaptation strategies.

\section{CONCLUSION}

This paper has set out a number of considerations to encourage the provision of more appropriate climate services information

\section{REFERENCES}

Allen, M., Raper, S., and Mitchell, J. (2001). Uncertainty in the IPCC's Third Assessment Report. Science 293, 430-433.

Arvai, J., and Rivers, III. (2013). Effective risk communication. New York, NY: Routledge.

Brasseur, G. P., and Gallardo, L. (2016). Climate services: Lessons learned and future prospects. Earth's Future 4, 79-89. doi: 10.1002/2015ef000338

Chester, M., Underwood, B. S., Allenby, B., Garcia, M., Samaras, C., Markolf, S., et al. (2021). Infrastructure resilience to navigate increasingly uncertain and complex conditions in the Anthropocene. NPJ Urb. Sustainab. 1:4. doi: 10.1038/ s42949-021-00016-y

CIRIA (2013). The International Levee Handbook. Report C731. London: CIRIA.

Digman, C., Balmforth, D., Kellagher, R., and Butler, D. (2006). Designing for exceedance in urban drainage - good practice. Report C635, London: CIRIA.

Environment Agency [EA] (2020). Flood risk assessments: climate change allowances. Bristol: Environment Agency.

Gouldby, B., Wyncoll, D., Panzeri, M., Franklin, M., Hunt, T., Hames, D., et al. (2017). Multivariate extreme value modelling of waves, winds and sea levels around the coast of England. Proc. Inst. Civ. Eng,.Mar. Eng. 1, 3-20. doi: 10.1680 /jmaen.2016.16 for end users. Use of the term climate services in situations unrelated to supporting adaptation to and mitigation of climate change should be avoided.

Better investment decisions could be made if Bayesian frameworks were used to assign probabilities to RCP scenarios. Associated predictions need to cover all types of climate change influences not just sea level rise and ideally provide concurrent time series to allow evaluation of dependencies. Guidance on climate information published by official bodies needs to adopt a consistent approach, with a clear narrative that describes the transition from science to guidance. The form in which climate services information is needed for the required end user decisions needs careful thought, including appropriate communication of the associated uncertainties using good practices and experiences from related sectors.

\section{DATA AVAILABILITY STATEMENT}

The original contributions presented in the study are included in the article/supplementary material, further inquiries can be directed to the corresponding author/s.

\section{AUTHOR CONTRIBUTIONS}

JS drafted overall manuscript and acted as editor. BG provided important material on climate services challenges and the nuclear power use case. DL and TM provided the information for the ports use case. All authors contributed to the article and approved the submitted version.

\section{FUNDING}

This work was funded by our employer, HR Wallingford.

Guthrie, G. (2021). Adapting to rising sea levels: how short-term responses complement long-term investment. Env. Resour. Econ. 78, 635-668. doi: 10. 1007/s10640-021-00547-z

Hausfather, Z., and Peters, G. P. (2020). Emissions-the 'business as usual' story is misleading. Nature 577, 618-620. doi: 10.1038/d41586-02000177-3

Hewitt, C., Mason, S., and Walland, D. (2012). The global framework for climate services. Nat. Clim. Change 2, 831-832. doi: 10.1038/nclimate1745

Le Cozannet, G., Nicholls, R. J., Hinkel, J., Sweet, W. V., McInnes, K. L., Van de Wal, R. S. W., et al. (2017). Sea level change and coastal climate services: the way forward. J. Mar. Sci. Eng. 5:49. doi: 10.3390/jmse504 0049

Lumbroso, D., and Woodhouse, G. (2014). Future Climate Change for Africa - The use of climate services for decision making in the port sector. Report MAR5322-RT003-R02-00, HR Wallingford: Wallingford.

Morriss, P. (1977). Combining Expert Judgments: A Bayesian Approach. Manag. Sci. 23, 679-693. doi: 10.1287/mnsc.23.7.679

National Committee on Coastal and Ocean Engineering [NCCOE] (2004). Guidelines for Responding to the Effects of Climate Change in Coastal and Ocean Engineering, 2004 Update. Engineers Australia: The National Committee on Coastal and Ocean Engineering. 
Nicholls, R. J., Hanson, S. E., Lowe, J. A., Warrick, R. A., Lu, X., and Long, A. J. (2014). Sea-level scenarios for evaluating coastal impacts. Wiley Interdisciplinary Reviews: Climate Change, 5, 129-150. doi: 10.1002/wcc.253

Office for Nuclear Regulation and Environment Agency [ONR and EA]. (2017). Principles for Flood and Coastal Erosion Risk Management, Joint Advice Note, Version 1. Redgrave Court: Office for Nuclear Regulation.

Office for Nuclear Regulation and Environment Agency [ONR and EA]. (2020). Use of UK Climate Projections 2018 (UKCP18) Position Statement - November 2020 Revision. Redgrave Court: Office for Nuclear Regulation.

Office for Nuclear Regulation [ONR]x. (2018). External Hazards. Report NS-TASTGD-013 Revision. Redgrave Court: Office for Nuclear Regulation, 7.

Oppenheimer, M., Little, C., and Cooke, R. (2016). Expert judgement and uncertainty quantification for climate change. Nat. Clim. Change 6, 445-451. doi: $10.1038 /$ nclimate2959

Palmer, M., Howard, T., Tinker, J., Lowe, J., Bricheno, L., Calvert, D., et al. (2018). UKCP18 Marine report - November 2018. Exeter, The Met Office. Bristol: Environment Agency.

PIANC - World Association for Waterborne Transport Infrastructure. (2020). Climate change adaptation planning for ports and inland waterways. Report 178. Brussels: PIANC.

Qian, Y., Jackson, C. S., Giorgi, F., Booth, B., Duan, Q., Forest, C., et al. (2016). Uncertainty quantification in climate modeling and projection. Bull. Am. Meteorol. Soc. 97, 821-824. doi: 10.1175/BAMS-D-15-00297.1

Riahi, K., Van Vuuren, D. P., Kriegler, E., Edmonds, J., O’neill, B. C., Fujimori, S., et al. (2017). The shared socioeconomic pathways and their energy, land use, and greenhouse gas emissions implications: an overview. Glob. Environ. Change 42, 153-168.

Royal Society. (2014). Resilience to extreme weather. Science Policy Centre report 02/14, London: The Royal Society.

Serinaldi, F. (2015). Dismissing return periods! Stoch Environ. Res. Risk Assess 29, 1179-1189. doi: 10.1007/s00477-014-0916-1

Smith, R., Tebaldi, C., Nychka, D., and Omearns, L. (2009). Bayesian Modeling of Uncertainty in Ensembles of Climate Models. J. Am. Stat. Assoc. 2009, 97-116. doi: 10.1198/jasa.2009.0007

Stenek, V., Amado, J. C., Connell, R., Palin, O., Wright, S., Pope, B., et al. (2011). Climate risk and business: ports. Washington, D.C: International Finance Corporation.
Tebaldi, C., Smith, R., Nychka, D., and Omearns, L. (2005). Quantifying Uncertainty in Projections of Regional Climate Change: A Bayesian Approach to the Analysis of Multimodel Ensembles. Journal of Climate g1524-g1540. doi: 10.1175/JCLI3363.1

United Nations Office for Disaster Risk Reduction [UNISDR] (2015). Sendai Framework for Disaster Risk Reduction 2015-2030. Geneva: UNISDR.

Vousdoukas, M. I, Mentaschi, L., and Hinkel, J. (2020). Economic motivation for raising coastal flood defenses in Europe. Nat. Commun. 11:2119. doi: 10.1038/ s41467-020-15665-3

Wong, P. P., Losada, J. P., Gattuso, J., Hinkel, A., Khattabi, K. L., McInnes, Y., et al. (2014). Coastal systems and low-lying areas. Cambridge, MA: Cambridge University Press, 361-409.

Woodward, M., Gouldby, B., Kapelan, Z., Khu, S. T., and Townend, I. (2012). Real options in flood risk management decision making. J. Flood Risk Man 4, 339-349. doi: 10.1111/j.1753-318x.2011. 01119.x

Woodward, M., Kapelan, Z., and Gouldby, B. (2014). Adaptive Flood Risk Management Under Climate Change Uncertainty Using Real Options and Optimization. Risk Analysis 34, 75-92. doi: 10.1111/risa.12088

Conflict of Interest: The authors declare that the research was conducted in the absence of any commercial or financial relationships that could be construed as a potential conflict of interest.

Publisher's Note: All claims expressed in this article are solely those of the authors and do not necessarily represent those of their affiliated organizations, or those of the publisher, the editors and the reviewers. Any product that may be evaluated in this article, or claim that may be made by its manufacturer, is not guaranteed or endorsed by the publisher.

Copyright (C) 2021 Simm, Gouldby, Lumbroso and Matthewson. This is an openaccess article distributed under the terms of the Creative Commons Attribution License (CC BY). The use, distribution or reproduction in other forums is permitted, provided the original author(s) and the copyright owner(s) are credited and that the original publication in this journal is cited, in accordance with accepted academic practice. No use, distribution or reproduction is permitted which does not comply with these terms. 